\title{
Hormone-Induced Protection Against Breast Cancer
}

\author{
Lakshmi Sivaraman • Daniel Medina
}

Published online: 18 February 2009

(C) Springer Science + Business Media, LLC 2009

Erratum to: J Mammary Gland Biol Neoplasia (2002) 7: 77-92 DOI 10.1023/A:1015774524076

The original version of this article unfortunately contained a mistake on the references. The reference cited as 41 in Table 1 is really reference 42 . From the second column on page 81 starting with reference listed as 43 until the end of the text on page 90 , all the references from $43-84$ should be read as references 41-82. All these references are two off. There are no references which are listed in the paper as 83 and 84 . The one exception is on page 87 , last paragraph, where reference 59 ("The results of Abrams-") is correct and not out of order.

The online version of the original article can be found at: http://dx.doi. org/10.1023/A:1015774524076.

L. Sivaraman · D. Medina $(\triangle)$

Department of Molecular and Cellular Biology,

Baylor College of Medicine,

1 Baylor Plaza,

Houston, TX 77030, USA

e-mail: dmedina@bcm.tmc.edu 